Hansen, I. L., Brown, R. E., Shaffer, R. D. \& Crawford, M. A. (ig66). E. Afr. med. J. 43, 489.

Lambrecht, F. L. (1966). E. Afr. Wildl. F. 4, 89.

Lamprey, H. E. (1963). E. Afr. Wildl. $\mathcal{F} . \mathbf{1}, 63$.

Laws, R. M. \& Parker, I. S. C. (1968). Symp. zool. Soc. Lond. no. 2 I.

McCullagh, K. \& Lewis, M. G. (1967). Lancet ii, 492.

Robins, E. (1963). Africa's Wildlife: Survival or Extinction? London: Odhams Press Ltd.

Scott, P. P. (1968). Symp. zool. Soc. Lond. no. 2 I.

Schmidt-Nielsen, K. (I964). Desert Animals : Physiological Problems of Ireat and Water. Oxford: Clarendon Press.

Sikes, S. K. (1968a). Proc. R. Soc. Med. 6r, I60.

Sikes, S. (1968b). Symp. zool. Soc. Lond. no. 21.

Simon, N. (1962). Wildlife of Kenya (Between the Sunlight and Thunder). London: Collins.

Sinclair, H. M. (1964). In Lipid Pharmacol., pp. 237-273. [R. Paolett, editor.]. New York: Academic Press Inc.

Sinclair, H. M. (I968). Symp. zool. Soc. Lond. no. 2 I.

Stewart, D. R. M. \& Stewart, J. (г 963). Il E. Afr. nat. Hist. Soc. 24, I.

Taylor, C. R. (1968). Symp. zool. Soc, Lond. no, 2 I.

Taylor, C. R. \& Lyman, C. P. (1967). Physiol. Zoöl. (In the Press.)

Treus, D. B. \& Kravchenko, D. (т968). Symp. zool. Soc. Lond. no. $2 \mathrm{I}$.

Whitehead, R. G. (1964). Lancet i, 250 .

Whitehead, R. G. (1965). Lancet ii, 567 .

\title{
Methods of studying the food habits of some wild ungulates in Uganda
}

\author{
By C. R. Field, Nuffield Unit of Tropical Animal Ecology, \\ Queen Elizabeth Park, Uganda
}

\section{Introduction}

Large numbers of a heterogenous assembly of mammals occur in East Africa, and in certain areas their biomass compares favourably with some of man's most intensively managed ranch land (Talbot \& Talbot, r963; Petridges \& Swank, I965). Conspicuous for their high biomasses, some parts of the Nile basin support about $25000 \mathrm{~kg} / \mathrm{km}^{2}$ (6I tons/square mile) of large mammals (Bourlière, 1965).

\section{The present study}

The many and varied ungulates which feed on apparently the same vegetation appear to conflict with the principle of the ecological separation of species (Gause, I934). Two hypotheses have been suggested in an attempt to reconcile these observations with the Gausian theory: ( I) a high primary production of vegetation permits high secondary biomasses; (2) a variety of herbivores may utilize the vegetation spectrum more fully.

The study area, the Queen Elizabeth Park in the Uganda Rift Valley, is more suited to plant growth than most grassland ecosystems, having volcanic soils, high radiation and moderate rainfall with good seasonal distribution. Primary productivity studies are planned in conjunction with the International Biological Programme; the present work, however, investigates the second hypothesis as follows:

(I) To test the concept of ecological separation of species based on food habits.

(2) To determine some of the factors affecting the food habits of large herbivores.

(3) A special study of the influence of a dominant herbivore, the hippopotamus (Hippopotamus amphibus Linn.) on other species through their diet. 


\section{Methods}

Elton (1927) recommended 'the patient collecting of all kinds of information about the food of the species being studied' and 'a combination of studies at the species and community level'. Although several of the methods he mentioned are used to study food habits some are not readily applicable or have limitations under East African conditions.

Animal distributions. Animal distributions may indicate association with vegetation communities where clearly defined vegetation types occur, for example with browsing animals in Tanzania (Lamprey, ${ }^{96} 63$ ). In savannah grasslands many species of plant are closely intermingled and distribution surveys are less precise, although greater precision is possible with aerial photography (Watson, 1967 ).

Animal censuses were used as a base-line to show the separation of large mammals and to suggest some of the causes. Monthly censuses of ten areas were carried out by vehicle by members of the Nuffield Unit from 1963 to 1967 inclusive. The areas represented particular plant and animal communities and covered about a tenth of the $76_{4}$ square mile Park. The distribution of ungulates, surface water and recent fires was plotted on maps of the areas. Ungulates within squares of a $400 \mathrm{~m}$ ( 16 hectare) grid were meaned separately for all wet and dry seasons. The incidence of fire and water in the squares was also summarized. Distributions of plant species were mapped in the areas by recording quadrats at random intervals along transects.

The wet and dry seasons distributions of ungulates were tested statistically against the vegetation communities, fire and water present in their squares. The occurrence of species in squares was investigated using the chi-square test and differences between species means in occupied squares by Student's $t$ test.

Examination of alimentary tract contents. It is necessary to examine ingested food to determine whether the plant-herbivore relationship is dietary or otherwise.

Mouth samples reflect food ingested at one moment or favour items, such as awned seeds lodged among the teeth. Similarly, samples of cud from tame animals or from fistulas are unrepresentative since even stomach contents may be stratified (Warner, I962).

Comprehensive sampling of stomach contents necessitates cropping animals. In the USA, where hunting is common, analyses are simplified by the gross nature of the browse consumed and the use of sieves to separate particles of different size (Dirschl, 1962). In the Park, hippopotamus cropping is a form of management to restore their equilibrium with the vegetation (Bere, 1959). This and five other ungulate species have provided ecological information including data on food habits (Laws \& Field, 1964).

Stewart (1967), confirmed that microscopic analyses of faeces, based on interspecific differences in epidermal characteristics of digested grasses is valid with limitations under East African conditions. The author has used the technique to analyse stomach contents from more than 500 of the six species mentioned. Six samples were collected from each species in three areas with different types of vegetation during each of the four seasons. Advantages of this method include (a) elimination of selective digestion of different plant species by the lower gut, and (b) $27(2) 5$ 
the availability of other information not readily obtainable from living animals, e.g. age and sexual condition.

Methods of faecal preparation and analyses have been summarized by Stewart (1965, 1966) and modifications in stomach samples by Field (1968a). Interpretation is limited to qualitative information and quantitative information on a frequency basis about the species ingested. The availability of each species in the sward is compared separately with their presence in stomachs. Where availability varies between areas the absence of corresponding variation in stomachs may suggest preferences. Within a vegetation type the comparison of inter- and intra-specific variation in dietary intake may reveal significant differences in food habits between species. Observations for the four seasons of the year are analysed to determine seasonal overlap of diets at which time competition might be expected.

Direct feeding observations. The method of direct observation was developed by Buechner (1950) for pronghorn antelope (Antilocapra americana) and later used by Eddy (196r), Harper (I962) and White (I962) on other species which browsed discrete and easily identified vegetation. Darling (1960), Lamprey (I963) and Napier Bax \& Sheldrick (1963) applied it to browsing species in Africa. In savannah plains, however, it is difficult to identify species grazed by animals which cannot be approached closely. Nevertheless, in the Park a herd of I 30 buffalo was amenable to close observation for 13 months (Ficld, 1968a) whilst waterbuck and topi, Damaliscus korrigum Ogilby, were studied more briefly. Records were made in inflorescences protruding from their mouths and may therefore favour flowering seasons.

The use of tame animals overcomes the difficulty of identification of food items. Information on plant parts consumed, seasonal variation in diet and methods of feeding has been obtained in most seasons for hippopotamus, warthog, antelope and buffalo, for the latter with four different types of vegetation.

Eight dominant species of grass were collected monthly for physical and chemical analyses. Leaves, stems and inflorescences were analysed separately. Palatability factors in these grasses such as tannins and oils have been investigated by BateSmith \& Swain (1967).

Hippopotamus grazing experiments. Hippopotamus need water to avoid diurnal desiccation (Luck \& Wright, 1964); hence their grazing is limited to the vicinity of their aquatic habitats. In some dense populations adult food intake may reach $I 45^{\circ} \mathrm{kg}(\mathrm{I} \cdot 4$ tons) dry weight per square mile per night. This rapidly affects the composition of the plant community by reducing less aggressive species and diversifying the habitat for colonization by opportunistic annuals.

This effect was studied by the elimination of hippopotamus and by overgrazing small pens with tame animals. The vegetation changes in about 25 square miles, where 1000 hippopotamus were eliminated, were recorded in 5 successive years. Frequency and foliar and basal cover records were made in ten plots at varying distances from the hippopotamus population.

\section{Observations}

Animal distributions. Results suggest that vegetation, fire and water may each 
influence the distribution of large mammals under certain conditions and that they are also affected by rainfall. Observations from the different vegetation communities of the study areas combine to give apparent preference sequences. For example, buffalo appear to prefer Cymbopogon afronardus least, followed by coarse Imperata cylindrica and short Microchloa kunthii, then Bothriochloa species, Hyparrhenia filipendula and Themeda triandra, whilst Sporobolus pyramidalis is most preferred. In the rains preferences are less precise whilst in the dry season Capparis tomentosa is also preferred. The presence of water in wallows is apparently preferred whilst fire has a mixed effect on distribution.

Nocturnal feeding patterns have been observed by Spinage (personal communication) for waterbuck, Kobus defassa ugandae, and by Neumann, Grimsdell \& the author (unpublished) for buffalo, Syncerus caffer Sparrman. It is therefore likely that some of the diurnal distributions reflect preferred resting places rather than food sources. Similarly the warthog, Phacochoerus aethiopicus Pallas, although diurnal, feeds more in the evening (Frädrich, 1965), by which time most censuses had been completed.

Analyses of stomach contents. Preliminary results (Field, 1967) suggest the following:

(I) Within an area diets of different herbivore species often overlap. This is more pronounced for some plant species than others and at certain times of the year. However, it is not clear whether the overlap in diets involves interspecific competition for food.

(2) Some samples differ markedly from the sward composition, suggesting selection of specific food items; others, however, vary between areas with availability. Nevertheless, the persistence of certain species in the diet even when rare in the sward implies considerable selection.

Direct observations. Observations on tame and wild animals (Field, 1968a,b) confirm interspecific differences in preferences for certain plant species. When vegetation is actively growing, as in the rains, there is considerable overlap in diets. During the dry season, when competition might be expected, there is less overlap and greater selection except where vegetation is much reduced by hippopotamus.

Food habits of buffalo vary little between areas, which confirms that they reflect active preferences and not merely availability. Some variation in preference for a plant species occurs between areas subject to different grazing pressures or fire regimes suggesting that growth stage influences choice of food. Seasonal changes in growth and proportions of the physical and chemical components of the plant support this.

The method of grazing determines the levels through which an animal feeds and therefore what portion of a sward is available to it. Mouth size and mobility determine the degree of selection that may be made by an animal within a feeding level.

The physical nature of grasses, in particular their stem to leaf ratio, appears to influence species eaten by coarse grazers like buffalo. Within a grass species, 
however, the proportion of dead leaf silica, green leaf carbohydrate and possibly other factors may affect seasonal preference differences.

Specific palatability factors such as oils and tannins may be repellant to members of the Andropogoneae, but they protect a grass only when the grazing animal has alternative vegetation to choose from.

Observations confirm that selective grazing enables the herbivore to consume a diet of a much higher nutritive value than that of the average sward. Browsing and new growth after burning may alleviate the low nutrient intake from grazing in the dry season.

Fluctuations in the nutritional value of the diet are believed to be the proximal cause of the seasonal reproductive cycle of buffalo and the ultimate cause in hippopotamus. Where the latter are numerous gross reduction in food may limit growth at times of climatic extreme.

Hippopotamus grazing experiments. Changes with the removal of hippopotamus are summarized as follows:

(I) A large initial increase in frequency of nearly all plant species in plots within I mile of the hippopotamus population.

(2) Erect grasses continued to increase at the expense of creeping and mat-forming species. Bare patches caused by hippopotamus overgrazing were stabilized and recolonized, short-lived annuals being replaced by perennials.

(3) The initial changes declined and vegetation became subject to small-scale fluctuations owing to varying climatic conditions and a long-term change, resulting from increased burning facilitated by improved foliar cover. Foliar increases were large initially and later fluctuated considerably owing to climatic changes and fire; however, recovery from the latter was usually rapid and complete.

\section{Discussion}

Hippopotamus are intensive grazers destroying vegetation in large patches. In small numbers they are useful since they diversify the habitat and stimulate plant growth; they also maintain wallows and indirectly reduce the spread of fires. The Park policy is therefore to maintain the population at twenty per square mile.

Since the removal of man there has been little or no predator control of hippopotamus or elephant. This is largely due to their size since unprotected calves may be taken by lion, Panthera leo Neumann. The resulting population increase has been accompanied by a rare example of vegetation defoliation. Fortunately, the most persistent perennial grass, Sporobolus pyramidalis, is palatable to most species whilst annuals are eaten by warthog and browse by buffalo.

In large numbers hippopotamus compete with other species by reducing the quantity of available herbage and by affecting the composition and lowering the nutritional value of the remaining vegetation. Hippopotamus, elephant (Loxodonta africana Blumenbach), and possibly buffalo, appear to undergo reduced fertility and higher calf mortality (Laws, 1967 ) when under nutritional stress. This nutritional limit on their populations although greatest in the dry seasons permits some vegetation to reach maturity without serious grazing damage. The rapid attainment 
of a plant's full genetic potential with high stem to leaf ratio, low protein content or accumulation of repellants in the mature leaf, also acts against grazing animals, in particular large coarse feeders which are less able to select parts of plants. In these species at least, the absence of the predatory control suggested by Hairston, Smith \& Slobodkin (1960) appears to have been filled by a nutritional control of their populations.

The author wishes to thank the committee and staff of the Nuffield Unit of Tropical Animal Ecology and the Trustees and staff of the Uganda National Parks for their help and co-operation.

\section{REFERENCES}

Bate-Smith, E. C. \& Swain, T. (1967), Nature, Lond. 2r3, 1033.

Bere, R. M. (1959). Oryx 5, II6.

Bourlière, F. (1965). Zoologica Africana r, 199.

Buechner, H. K. (1950). Am. Midl. Nat. 43, 275.

Darling, F. F. (r960). Wildlife in an African Territory, ist ed. London: Oxford University Press.

Dirschl, H. J. (1962). F. Wildl. Mgmt 26, 327.

Eddy, T. A. (1961). F. Wildl. Mgmt 25, 248.

Elton, C. (1927). Animal Ecology, ist ed. London: Sidgwick \& Jackson Ltd.

Field, C. R. (1967). Zoologica Africana 3. (In the Press.)

Field, C. R. (1968a). Symp. zool. Soc. Lond. no, 21.

Field, C. R. (I968b). Food habits of some wild ungulates in Uganda. PhD Thesis, University of Cambridge.

Frädrich, H. (1965). Z. Tierpsychol. 22, 328.

Gause, G. F. (1934). The Struggle for Existence. Baltimore: Williams \& Wilkins Co.

Hairston, N. G., Smith, F. E. \& Slobodkin, L. B. (1960). Am. Nat. 94, 42 I.

Harper, J. A. (r962). F. Wildl. Mgmt 26, 97.

Lamprey, H. F. (1963). E. Afr. Wildl. \%. 1, 63.

Laws, R. M. (1967). In East African Wildlife-Land use Symposium. (In the Press.)

Laws, R. M. \& Field, C. R. (1964). Report and Accounts of the Uganda National Parks, p. 28. Kampala: Uganda Argus Ltd.

Luck, C. P. \& Wright, P. G. (1964). Q. $\mathscr{l} l$ exp. Physiol. 49, 1.

Napier Bax, P. \& Sheldrick, D. L. W. (1963). E. Afr. Wildl. F. I, 4 o.

Petridges, G. A. \& Swank, W. G. (1963). Zoologica Africana 1, 209.

Stewart, D. R. M. (1965). Bot. $7 b .84,63$.

Stewart, D. R. M. (1966). A technique for studying the food preferences of grazing herbivores. $\mathrm{PhD}$ Thesis, University of East Africa.

Stewart, D. R. M. (1967). F. appl. Ecol. 4,83.

Talbot, L. M. \& Talbot, M. H. (1963). Trans. N. Am. Wildl. Conf. 28, 465.

Warner, A. C. I. (1962). F. gen. Microbiol. 28, 1 19.

Watson, R. M. (1967). Population ecology of the wildebeeste in the Serengeti. PhD Thesis, University of Cambridge.

White, R. W. (1962). F. Wildl. Mgmt. 25, 404.

\section{Application of findings of research in animal nutrition to man}

\section{By W. F. J. Cuthbertson, Glaxo Research Ltd, Greenford, Middlesex}

Studies on animal nutrition have been and will continue to be of great importance. Such investigations can be used to check the dietary origin of certain human diseases, 